\title{
Picturing Future Imaginaries for Innovations Towards Sustainability Transitions
}

\author{
Rumy Narayan \\ rumy.narayan@uva.fi | University of Vaasa, School of Management, Finland \\ Letter from Academia
}

\begin{abstract}
Sustainability is about the world we need but are not quite sure how to garner consensus about what it should be. As it is yet to exist, we can always imagine what it could be and design networks for this transition. Such innovation networks fueled by imaginaries could offer countless opportunities for transition incentivized through applications like tokens, available through decentralized ledger technologies (DLTs).
\end{abstract}

Keywords. Sustainability; Network; Imaginaries; Transition; Innovation; Consensus; Tokens; DLTs.

Cite paper as: Narayan, R., (2019). Picturing Future Imaginaries for Innovations Towards Sustainability Transitions - Letter from Academia, Journal of Innovation Management, www.open-jim.org, 7(3), 10-14. 
The Canadian historian Benoit Godin, in his extensive work ${ }^{1}$ on innovation, notes that when the term first appeared in the thirteenth century legal texts for renewing contracts, it signified newness not creativity. According to Godin, the framing ${ }^{2}$ was not particularly positive and it was through the word's association with invention related to science and technology during the Industrial Revolution, that it acquired a positive and prestigious implication. However, it was Joseph Schumpeter, the Austrian economist, who framed its meaning to reflect acts of intellectual creativity, thus infusing the ideas behind the word with imagination. Within Schumpeter's framing this form of creativity was not given any overt economic objective, rather, it was to illustrate the various ways in which inventions could be imagined to reflect unique changes in ways to run businesses (Fagerberg, 2007). For Schumpeter, the value was distributed, and not concentrated in one final objective. This perspective gains critical relevance in the information age.

It is within this framing that innovation acquires significance for transitions to sustainability, mainly because sustainability as a concept is abstract and is difficult to grasp within the current socioeconomic and technological paradigms (Adams et al., 2016; Seebode et al., 2012; Smith et al., 2010) and requires network building infused with imaginaries. Innovation, with a distributed understanding of value creation could open up possibilities for new combinations (Hart and Milstein, 1999) and network pictures inspired by imaginaries enable such combinations for transitions to sustainability. The possibilities for such combinations have always existed, but now with applications like tokens made available on decentralized ledger technologies (DLTs) we might have the tools to realize them.

Network pictures are strategic tools used by managers to make sense of the relationships within business networks (Abrahamsen et al., 2016; Hopkinson, 2015). Managers' decisions about how to interact, mobilize, and influence other actors through connected relationships is understood through their network picturing processes. Therefore, it is also useful as a strategic tool for fostering innovation networks (Möller, 2010). However, even as innovation garnered popularity and been credited for curing all sociotechnical issues, it has also been critiqued for not paying adequate attention to why such issues emerged in the first place (see Pfotenhauer and Jasanoff, 2017). As a result, there is a fundamental disconnect between the fruits of innovation and its effects. For example, using plastic for packaging due to the material's durable and indestructible properties is absurd if the packaging is meant to be discarded. Further, models of innovation where particular innovations are replicated without paying attention to the diverse contexts and their specific needs has fueled calls for linking innovation to sociotechnical imaginaries (Pfotenhauer and Jasanoff, 2017). In STS (science and technology studies) and policy research there is a push towards investigating images of the future related to innovations in specific contexts. By infusing imaginaries, innovation processes take into consideration what is imaginable and possible within distinct social, political, and historical contexts. In doing so, they offer a thread of continuity and stability by extending existing frames of reference from the past into the future, and mitigating the disruptive quality of innovation processes.

Combining imaginaries with network pictures expands the perspective of innovation to include a deeper societal engagement. One of the critical insights from Godin's account of the history

\begin{tabular}{ll}
\hline 1 & http://www.csiic.ca/en/the-idea-of-innovation/ \\
2 & http://www.csiic.ca/PDF/IntellectualNo6.pdf
\end{tabular} 
of innovation is that the word has always been infused with the social and cultural climate of a particular time, and the history that this climate emerged out of. The interesting thing about innovation is not that it offers a singular way of solving problems; it is to understand the purpose; and the purpose is to aid in the process of creation, rather than arriving at a final solution. One can extrapolate from Godin's account that the term innovation enables the creation of ontological frameworks allowing people of a particular time grasp its meaning within their context, and in that innovation is, at its core, a creative practice. This practice requires an effective mechanism that would enable the weaving of organizational networks for sustainability.

Decentralized ledger technologies (DLTs) like the blockchain, have been repositioned as mechanisms for mobilizing far more than just payment reconciliation systems (Glaser, 2017; Kewell et al., 2017). The potential of such technologies in enabling a new system of value that clearly recognizes the coordination mechanism underlying our socioeconomic systems for increased social sharing remain underexplored. There are various layers of value creation that range from production of value, the record of value, to the actualization of value (see Pazaitis et al., 2017). In capturing and recording this information, DLTs make the various social interactions tangible and visible, and opens up opportunities for infinite combinations for innovations (Chen, 2018) that could enable transitions towards sustainability. These combinations could be incentivized by creating digital tokens to represent the value being exchanged and open up innovations across the layers of value.

Understanding innovation from this standpoint will require a different set of questions that explores what it means to be innovative in this time, and new ways of understanding the world, in order to offer us a different perspective. The questions, therefore, need to be framed within the general idea of how might one live. Framing questions within this idea is distinct from the past where the quest was to answer, how one should live and later to how one should act (May, 2003). The questions related to how one should live have been the preoccupation of ancient philosophers, where there is an assumption of hierarchy, a sort of transcendent order that we are required to adhere. This was followed by how should one act, where the individual takes precedence. The question of our time takes into cognizance the relevance of those past questions within their contexts to arrive at the question that asks - how might one live. This question acknowledges that our reality is chaos, and that is precisely why we are unable to coherently articulate or describe what it is we mean by sustainability. We do not have the tools to grasp the complexities that sustainability entails but we can use ontological systems devised of concepts that help us bring a semblance of order to that chaos. Innovation could be seen as the art of concept creation. To describe the role of innovation, it is important to understand what has been its role throughout history and to begin transitions, we should be willing to engage with imaginaries from the past and the present as well as the future for network building.

The goal of innovation is not to offer a final and coherent vision of sustainability but to offer us a window through which we can witness how people have interpreted innovation to solve the problems that are relevant to their culture and time. When we understand innovation from this perspective then it offers us a goldmine of useful ideas and new ways of realizing them. 


\section{References}

Abrahamsen, M. H., Henneberg, S. C., Huemer, L., \& Naude, P. (2016). Network picturing: An action research study of strategizing in business networks. Industrial Marketing Management, 59, 107-119.

Adams, R., Jeanrenaud, S., Bessant, J., Denyer, D., \& Overy, P. (2016). Sustainability-oriented innovation: A systematic review. International Journal of Management Reviews, 18(2), 180205.

Chen, Y. (2018). Blockchain tokens and the potential democratization of entrepreneurship and innovation. Business horizons, 61(4), 567-575.

Fagerberg, J. (2007). A guide to Schumpeter. Confluence: Interdisciplinary Communications, 2008, 20-22.

Glaser, F. (2017). Pervasive decentralisation of digital infrastructures: a framework for blockchain enabled system and use case analysis.

Hart, S. L., \& Milstein, M. B. (1999). Global sustainability and the creative destruction of industries. MIT Sloan Management Review, 41(1), 23.

Hopkinson, G. C. (2015). Network graffiti: Interaction as sensemaking. Industrial Marketing Management, 48, 79-88.

Kewell, B., Adams, R., \& Parry, G. (2017). Blockchain for good? Strategic Change, 26(5), 429-437.

May, T. (2003). When is a Deleuzian becoming? Continental Philosophy Review, 36(2), 139153.

Möller, K. (2010). Sense-making and agenda construction in emerging business networks-How to direct radical innovation. Industrial Marketing Management, 39(3), 361-371.

Pazaitis, A., De Filippi, P., \& Kostakis, V. (2017). Blockchain and value systems in the sharing economy: The illustrative case of Backfeed. Technological Forecasting and Social Change, 125, 105-115.

Pfotenhauer, S., \& Jasanoff, S. (2017). Panacea or diagnosis? Imaginaries of innovation and the 'MIT model'in three political cultures. Social studies of science, 47(6), 783-810.

Seebode, D., Jeanrenaud, S., \& Bessant, J. (2012). Managing innovation for sustainability. R\&D Management, 42(3), 195-206.

Smith, A., Voß, J. P., \& Grin, J. (2010). Innovation studies and sustainability transitions: The allure of the multi-level perspective and its challenges. Research policy, 39(4), 435-448. 


\section{Biographies}

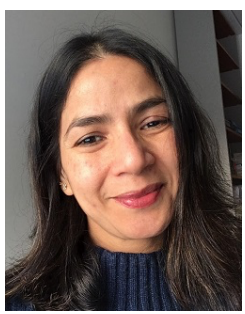

Rumy Narayan. Rumy studies transitions to sustainable energy systems. Her research interests fall within a framework of innovation possibilities that could potentially address pressing global challenges of our time, while stimulating societal and economic prosperity. This entails activating innovations across sectors, actors, and disciplines, while enabling experimentation, a complex process that needs appropriate tools for coordinating and managing diverse networks. Within this context, blockchain gains relevance for her research as it could be understood as an institutional and social technology for managing and coordinating disparate networks of actors. 